\title{
New Principle for Large-Scale Preparation of Purified Human Pancreas Islets
}

\author{
SUPANDI WINOTO-MORBACH, KARIN ULRICHS, GABY LEYHAUSEN, \\ AND WOLFGANG MÜLLER-RUCHHOLTZ
}

\begin{abstract}
Because successful human islet transplantation requires large quantities of viable islets that must be separated from the highly immunogenic exocrine tissue and because handpicking is too time-consuming and laborious to be clinically relevant, a new approach for solving this problem has been established in rat models. It is based on the principle that magnetic microspheres (MMSs) coupled to lectins with binding specificity for the exocrine tissue portion are trapped in an electromagnetic field, thus providing effluent islets of a high degree of purity. In this study our aim was to adapt this principle to human islet preparations. In this context our prime interest was focused on a lectin suitable for human pancreatic tissue. Of 19 different lectins tested, only 1, Wisteria floribunda agglutinin (WFA), is suitable, as shown by immunofluorescence, MMS-lectin binding, and magnetic separation. Diabetes 38 (Suppl. 1):146-49, 1989
\end{abstract}

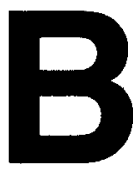

ecause handpicking of islets, a commonly used purification procedure in rodents, is impracticable for human material due to the large quantities of clean islets needed, there is a great demand for a more efficient approach to this problem (1). We previously reported on a very effective and simple purification procedure for collagenase-digested rat islets, based on magnetic microspheres (MMSs) coupled to a lectin with selective binding specificity for exocrine tissue (2). Our aim in this study was to adapt this technique to human islet material. Ulex europaeus agglutinin I (UEA-I), the lectin used for rat exocrine tissue, proved to be unsuitable for human tissue, because it also binds to endocrine cells. Thus, studies with crude-human islet preparations were focused on the anal-

From the Department of Immunology, Medical School, University of Kiel, Kiel, Federal Republic of Germany

Address correspondence and reprint requests to Dr. S. Winoto-Morbach, Department of Immunology, Medical School of the University of Kiel, Brunswikerstrasse 4, D-2300 Kiel, FRG. ysis of 18 other lectins in indirect immunofluorescence and binding studies with MMS-coupled lectins.

\section{MATERIALS AND METHODS}

Human islet preparation. Crude-human islet preparations were obtained from cadaveric pancreases according to the technique of Gray et al. (3) and stored in liquid nitrogen until further use. Of 18 preparations, only isolation 7 (consisting mainly of underdigested islets) and isolation 15 (consisting mainly of well-digested islets) were used for magnetic separation.

Lectins. The following lectins (agglutinins) were used: Anguilla anguilla (AAA), Bauhinia purpurea (BPA), Canavalia ensiformis (ConA), Dolichos biflorus (DBA), Erythrina cristagalli (ECA), Griffonia simplicifolia I (GSA-I), Griffonia simplicifolia II (GSA-II), Helix pomatia (HPA), Lens culinaris (LCA), Limulus polyphemus (LPA), Maclura pomifera (MPA), Arachis hypogaea (PNA), Ricinus communis I (RCA-I), Glycine max (SBA), succinyl Canavalia ensiformis (Succ. ConA), succinyl Triticum vulgaris (Succ. WGA), Ulex europaeus I (UEA-I), Triticum vulgaris (WGA), and Wisteria floribunda (WFA). Lectins were purchased from Medac (Hamburg, FRG).

Preparation of MMS and lectin coupling. The MMSs were prepared by modification of the basic procedure described elsewhere $(4,5)$. Briefly, $75 \mathrm{mg}$ bovine serum albumin (BSA) and $23 \mathrm{mg} \mathrm{Fe}_{3} \mathrm{O}_{4}$ were dissolved in $250 \mu \mathrm{l}$ distilled water, mixed with $25 \mathrm{ml}$ cottonseed oll, and sonicated in an icewater bath six times for 1 min each. The emulsion was immediately squirted into $150 \mathrm{ml}$ oil at $120^{\circ} \mathrm{C}$. The heat-stabilized MMSs were purified of oil by washing with acetone. Thereafter, they were activated with $2.5 \%$ glutaraldehyde, and after several washings, they were incubated with a lectin (20 $\mu \mathrm{g} \mathrm{lectin} / \mathrm{mg} \mathrm{MMS}$ ) in phosphate-buffered saline (PBS) for $2 \mathrm{~h}$. Finally, they were washed with PBS and stored in PBS $+0.02 \%$ azide $+1 \%$ BSA $+0.05 \%$ Tween at $4^{\circ} \mathrm{C}$. Before use, MMSs were washed with sterile $\mathrm{PBS} / 2 \%$ glucose several times and resuspended in RPMI-1640 medium with $10 \%$ fetal calf serum (RPMI-FCS). 
Fluorescence studies on isolated islets. Crude-islet preparations were tested with 19 lectins for their binding specificity to exocrine tissue: $100 \mu$ l of crude-islet suspension was incubated with $100 \mu$ fluorescein isothiocyanate (FITC)-labeled lectin (diluted 1:10 with PBS for 40 min at $4^{\circ} \mathrm{C}$ in the dark), and after three washings, it was prepared for microscopic evaluation on glass slides.

MMS binding studies on isolated islets. Lectin-coupled MMSs were bound to islets in the following manner: $200 \mu \mathrm{l}$ crude islet suspension was incubated with $20 \mu$ l (0.2 mg)
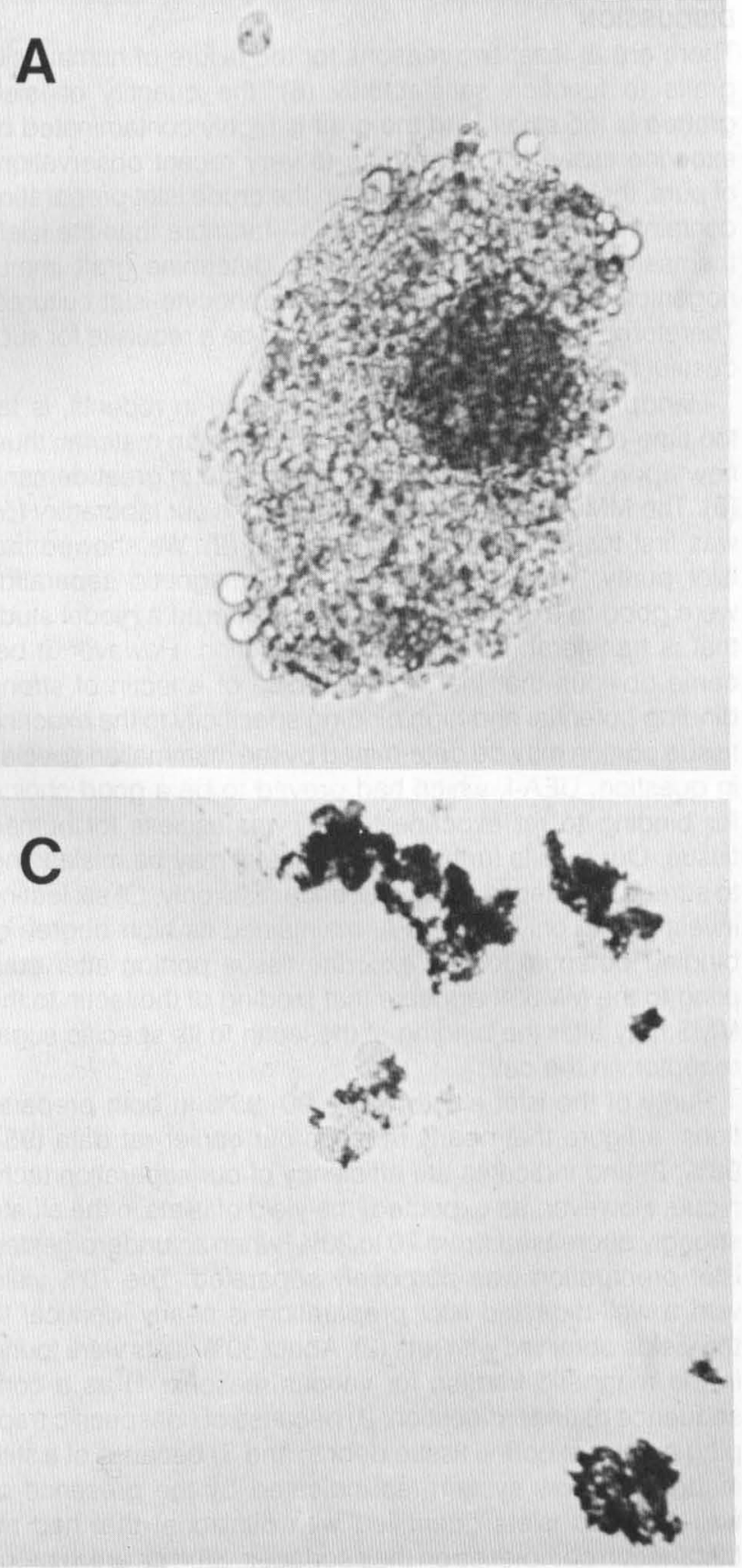

lectin-coupled MMS for $40 \mathrm{~min}$ on ice. MMS binding was evaluated microscopically.

Magnetic separation procedure. Approximately 200-300 crude islets were incubated with $2-3 \mathrm{mg}$ lectin-coupled MMS in $5 \mathrm{ml} \mathrm{RPMI-FCS} \mathrm{for} 40 \mathrm{~min}$ at $4^{\circ} \mathrm{C}$ in a $50-\mathrm{ml}$ culture flask. Binding of these MMSs to exocrine cells was tested microscopically. After addition of $5 \mathrm{ml}$ RPMI-FCS, the flask was positioned in an electromagnetic field of $800 \mathrm{G}$ for 4 min and $1500 \mathrm{G}$ for $2 \mathrm{~min}$. Thereafter, purified islets were collected from the bottom of the flask, but exocrine tissue
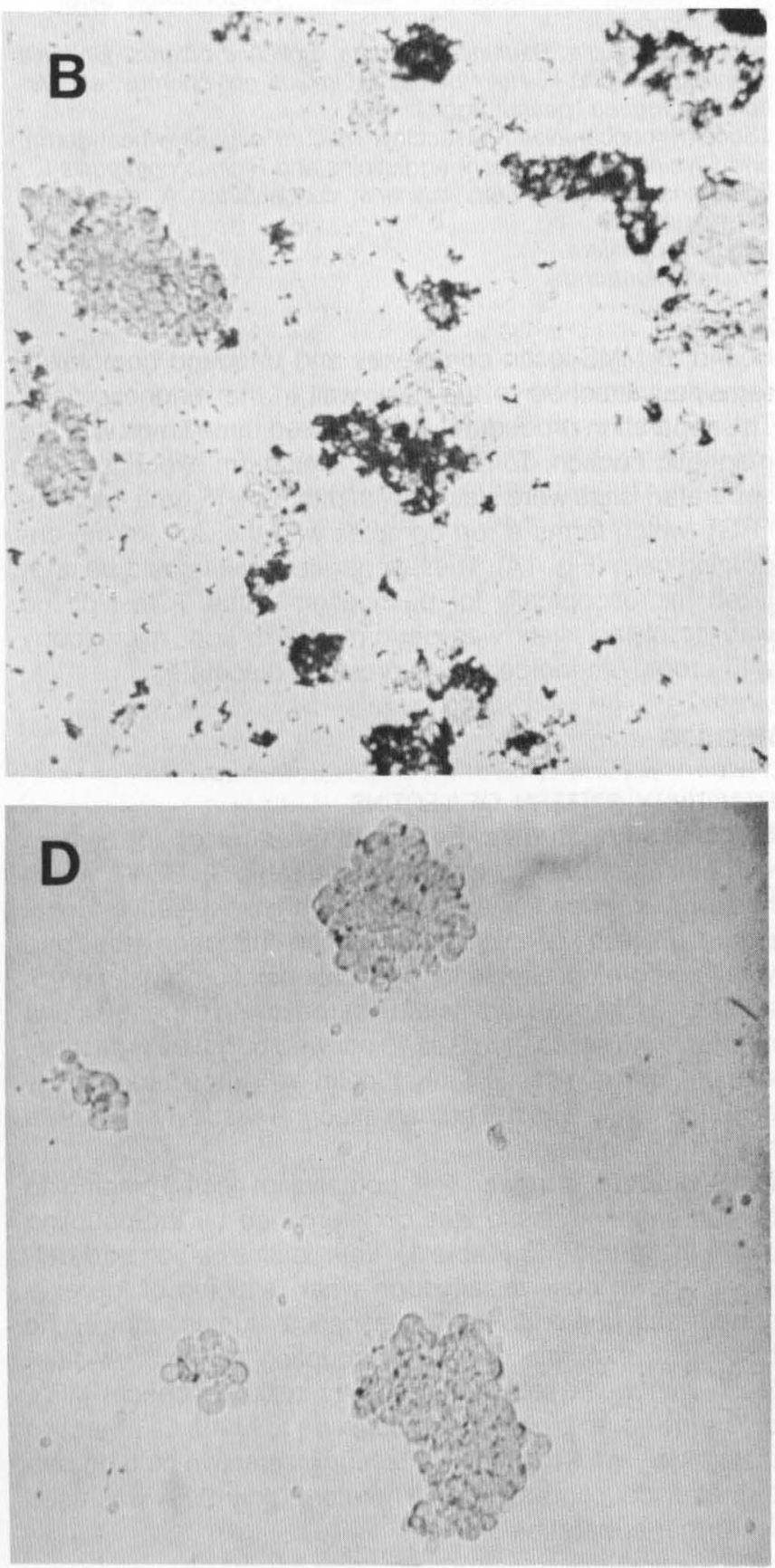

FIG. 1. A: underdigested human islet stained with dithizone; islet appears as dark spot in tissue center. B: crude human islet preparation incubated with Wisteria floribunda-coupled lectin magnetic microspheres before magnetic separation. $C$ : after magnetic separation exocrine cells were trapped in magnetic fraction. D: purified islets collected in eluate. $\times 550$. 
TABLE 1

Binding pattern of lectins to human exocrine or endocrine pancreas portion

\begin{tabular}{|c|c|c|c|c|c|c|c|}
\hline & \multirow[b]{2}{*}{ Binding } & \multicolumn{6}{|c|}{ Groups of lectins } \\
\hline & & $1^{*}$ & $2 \dagger$ & $3 \ddagger$ & $4 \S$ & $5 \|$ & 64 \\
\hline $\begin{array}{l}\text { Lectins coupled } \\
\text { to fluorescein }\end{array}$ & Exocrine & ++ & - & + & + & + & +++ \\
\hline isothiocyanate & Endocrine & + & - & - & - & - & - \\
\hline $\begin{array}{l}\text { Lectins coupled } \\
\text { to magnetic }\end{array}$ & Exocrine & $t+$ & & & - & - & ++ \\
\hline microspheres & Endocrine & + & & & - & $-1+$ & - \\
\hline
\end{tabular}

+++ , Strong; ++ , medium; + weak; - , no detectable bind. * Ulex europaeus.

†Anguilla anguilla, Bauhinia purpurea, Dolichos biflorus, Griffonia simplicifolia I and II. Helix pomatia, Limulus polyphemus, and Arachis hypogaea (peanut agglutinin).

¥Succinyl concanavalin A, succinyl Triticum vulgaris (wheat germ), and Glycine max (soybean) agglutinins and Ricinus communis I. \$Erythrina cristagalli. Lens culinaris, concanavalin A, and wheat germ agglutinin.

|Maclura pomifera.

TWisteria floribunda.

bound to MMS-lectin complexes and unbound complexes remained attached to the flask wall in the magnetic field. The separation procedure was repeated three times with the magnetic fraction. To distinguish islets from exocrine cells, separated islets were stained with dithizone (Sigma, Munich, FRG), which forms a red complex with the $\mathrm{Zn}^{2+}$ of the endocrine cells (Fig. 1A). Thus, separated islets could be analyzed microscopically for purification status. A test of the viability of the islets was performed with light microscopy with propidium iodide and fluorescein diacetate.

\section{RESULTS}

REACTIVITY PATTERN OF LECTINS

Fluorescence studies. Each lectin was tested for binding with at least three islet preparations (Table 1). UEA-I, which had proven in earlier studies to be highly selective for rat exocrine tissue (2), also stained human endocrine tissue and was therefore unsuitable for purification of human islet preparations. Eight of 19 lectins did not react with either exocrine or endocrine tissue, and 9 of 19 showed only weak reactivity with the exocrine tissue. Only 1 lectin, WFA, reacted strongly and selectively with the human exocrine tissue, i.e., not with the endocrine tissue.

MMS binding studies. The potential of lectin binding to human exocrine tissue was codetermined by the coupling of the lectin to MMS (Table 1). Four lectins, which had definitely shown positive, although weak, staining of the exocrine tissue portion in the fluorescence studies, showed no binding to exocrine cells after coupling to MMS. Another lectin with weak selective reactivity in fluorescence, MPA, also showed no binding after coupling to MMS. Of all lectins tested, only WFA maintained its highly selective binding pattern after coupling to MMS. Therefore, only WFA was used for further separation studies.

PURITY, YIELD, AND VIABILITY OF WFA-MMS-SEPARATED HUMAN ISLETS

Exemplary for the varying quality of collagenase digestion, two crude-islet preparations, 15 (most islets without exocrine rim) and 7 (most islets with exocrine rim), were chosen for WFA-MMS separation in the electromagnetic field. With preparation 15 the purity of the eluate (islets) was 90-95\%, and the yield of islets was $-70 \%$ when the results of the separation were analyzed with the dithizone-staining technique. With preparation 7 the purity of the eluate was again $\sim 90-95 \%$; however, the yield of islets was only $\sim 20 \%$. Typical results of a magnetic separation run with is et preparation 15 are shown in Fig. 1, B-D. Staining with propidium iodide and fluorescein diacetate revealed viability of islets (of both preparations) before and after magnetic separation of $\sim 90 \%$.

\section{DISCUSSION}

There are at least two reasons for the failure of human islet grafts to function satisfactorily (6): the quantity of islets grafted is too small, and the graft is highly contaminated by exocrine tissue (3). According to very recent observations of ours, the exocrine debris within the crude islet preparation contains numerous HLA-DR ${ }^{+}$cells - far more than the islets themselves-and thus may greatly determine graft immunogenicity, as revealed by mixed lymphocyte-islet cultures. Therefore, islet purification appears to be a requisite for successful human transplantation.

Handpicking of islets, well established in rodents, is far too time-consuming and laborious for human material; thus, new approaches to solve this problem are in great demand (3). The MMS technique, as developed in our laboratory (5), was first tested for rat islet purification (2). We showed that islet purity, yield, and function after magnetic separation were good to excellent. This was considered a model study that is transferable to the human situation. However, it became obvious that the proper choice of a lectin of strong binding potential and high binding specificity to the exocrine tissue portion may be determined by the mammalian species in question. UEA-I, which had proved to be a good choice for binding to rat exocrine tissue, was useless for human tissue. Our results further showed that it may be misleading to screen for a lectin in fluorescence tests only. Of six lectins investigated, only one, WFA, maintained its high degree of binding potential for the exocrine tissue portion after coupling to the MMS. It appears that binding of the lectin to the MMS may alter the binding of the lectin to its specific sugar receptor on the cell.

Purity of the islet eluate was $-90-95 \%$ in both preparations, a figure that nearly reaches our earlier rat data (95$98 \% ; 2$ ) and indicates the efficiency of our separation technique. However, as expected, the yield of islets in the eluate strongly decreased (from 70 to $20 \%$ ) when an underdigested islet preparation was purposely separated. The $70 \%$ yield with a well-digested islet preparation is nearly identical to the yields obtained with rats (2). About $30 \%$ islets were found in the magnetic fraction for various reasons: 1) as a consequence of underdigestion; 2) because of nonspecific trapping among exocrine tissue debris; and 3) because of a stillinadequate flow system, as indicated by the presence of well-digested islets (identified with dithizone) that had no MMS-lectin complexes on their surfaces. Studies are in progress to improve the flow system and to improve the yield by a subsequent separation run of the recovered and resuspended magnetic field fraction. Furthermore, repetitive runs may be performed at a lower electromagnetic field strength, 
allowing islets to pass that contain exocrine tissue rims as only minor components. Thereafter, $\mathrm{N}$-acetyl-D-galactosamine, the WFA-specific sugar, may be added to the resulting effluent fraction that would contain MMS to dissociate the MMS from cells. This approach has been shown to be nontoxic for human islet cells in recent preliminary tests. In conclusion, we hope that the principle described here is fast, simple, safe, and effective enough to become helpful for solving the problem of large-scale purification of islets for transplantation in humans.

\section{ACKNOWLEDGMENTS}

We thank B. Lütje, D. Hoffmann, and S. Stein for skillful technical assistance.

\section{REFERENCES}

1. Gray DWR, Morris PJ: Developments in isolated pancreatic islet trans plantation (overview). Transplantation 43:321-31, 1987

2. Müller-Ruchholtz W, Leyhausen G, Petersen P, Schubert G, Ulrichs K: A simple methodological principle for large scale extraction and purification of collagenase-digested islets. Transplant Proc 19:911-15, 1987

3. Gray DWR, McShane P, Grant A, Morris PJ: A method for isolation of islets of Langerhans from the human pancreas. Diabetes 33:1055-61, 1984

4. Kandzia J, Scholz W, Anderson M.JD, Müller-Ruchholtz W: Magnetic albumin/protein A immunomicrospheres. I. Preparation, antibody binding capacity and chemical stability. J Immunol Methods 75:31-41, 1984

5. Mülier-Ruchholtz W, Kandzia J, Leyhausen G: Cell separation with magnetic immunomicrospheres. In Cellular, Molecular and Genetic Approaches to Immunodiagnosis and Immunotherapy. Kano K. Mori $\mathrm{S}$, Sugisaki T, Torisu M, Eds. Tokyo, Univ. of Tokyo Press, 1987, p. 181-90

6. Alejandro R, Mintz DH, Noel J, Latif Z, Koh N Russelt E, Miller J: Islet cell transplantation in type I diabetes mellitus. Transplant Proc 19:2359-61, 1987 